\title{
Fluidized mining and in-situ transformation of deep underground coal resources: a novel approach to ensuring safe, environmentally friendly, low-carbon, and clean utilisation
}

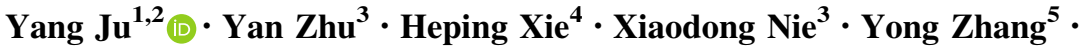 \\ Chang $\mathrm{Lu}^{3} \cdot$ Feng Gao ${ }^{2}$
}

Received: 23 May 2019/Revised: 28 May 2019/Accepted: 31 May 2019/Published online: 17 June 2019

(C) The Author(s) 2019

\begin{abstract}
Traditional coal mining and utilisation patterns are severely detrimental to natural resources and environments and significantly impede safe, low-carbon, clean, and sustainable utilisation of coal resources. Based on the idea of in situ fluidized coal mining that aims to transform solid coal into liquid or gas and transports the fluidized resources to the ground to ensure safe mining and low-carbon and clean utilisation, in this study, we report on a novel in situ unmanned automatic mining method. This includes a flexible, earthworm-like unmanned automatic mining machine (UAMM) and a coal mine layout for in situ fluidized coal mining suitable for the UAMM. The technological and economic advantages and the carbon emission reduction of the UAMM-based in situ fluidized mining in contrast to traditional mining technologies are evaluated as well. The development trends and possible challenges to this design are also discussed. It is estimated that the proposed method costs approximately $49 \%$ of traditional coal mining costs. The UAMM-based in situ fluidized mining and transformation method will reduce $\mathrm{CO}_{2}$ emissions by at least $94.9 \%$ compared to traditional coal mining and utilisation methods. The proposed approach is expected to achieve safe and environmentally friendly coal mining as well as lowcarbon and clean utilisation of coal.
\end{abstract}

Keywords In-situ fluidized mining · Unmanned automatic mining machine $\cdot$ Mine layout Coal resources $\cdot$ Low-carbon Environmental protection

Electronic supplementary material The online version of this article (https://doi.org/10.1007/s40789-019-0258-1) contains supplementary material, which is available to authorized users.

\section{Yang Ju}

juy@cumtb.edu.cn; yju@icloud.com

1 State Key Laboratory of Coal Resources and Safe Mining, China University of Mining \& Technology, Beijing, D11 Xueyuan Road, Beijing 100083, China

2 Frontier Scientific Research Centre for Fluidized Mining of Deep Underground Resources, China University of Mining \& Technology, 1 University Ave, Xuzhou 221006, China

3 School of Mechanics and Civil Engineering, China University of Mining \& Technology, Beijing, D11 Xueyuan RD, Beijing 100083, China

4 Institute of Deep Earth Science and Green Energy, Shenzhen University, Shenzhen 518060, China

5 School of Energy and Mining Engineering, China University of Mining \& Technology, Beijing, D11 Xueyuan RD, Beijing 100083, China

\section{Introduction}

Coal is the principal energy source globally and contributes to the sustainable development of economies (Wolde-Rufael 2010). The British Petroleum (BP) statistical review of world energy (2018) reported that electric power currently holds the single largest share of the energy market and accounted for over $40 \%$ of the primary energy in 2017 (BP 2018b). Coal is the dominant source of electric power and accounted for $38.1 \%$ of global electricity generation in 2017, which was approximately equal to the combined shares of natural gas (23.2\%) and hydroelectricity (15.9\%) (Fig. 1a) (BP 2018b). In addition, as shown in Fig. 1b, oil, coal, and natural gas are the dominantly consumed fuels worldwide, with coal accounting for $27.6 \%$ of the market share (BP 2018b). According to BP, the reserves-to-production ratio (i.e. ratio of remaining recoverable reserves of natural resources at the end of a year and production in that 


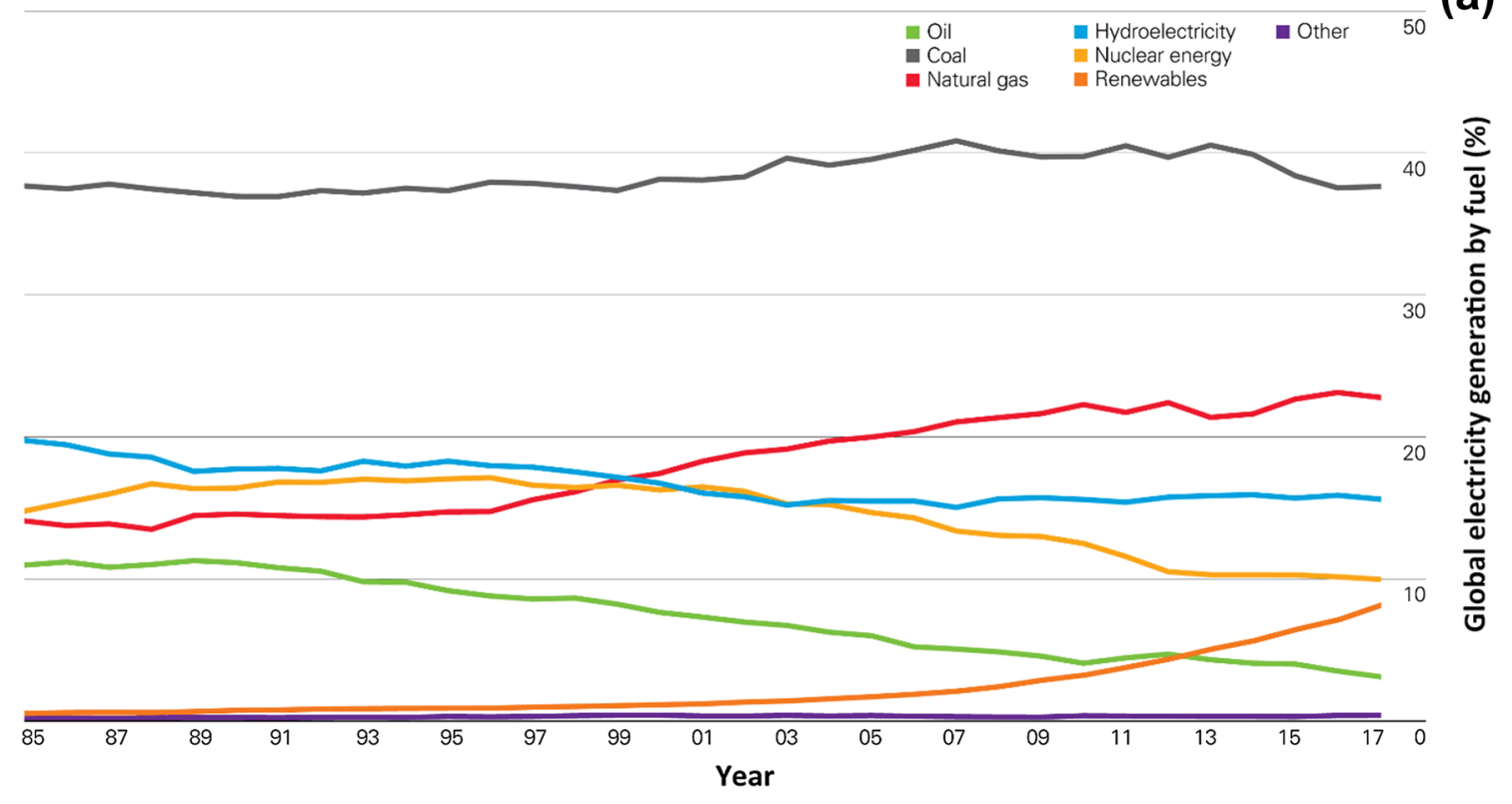

(a)

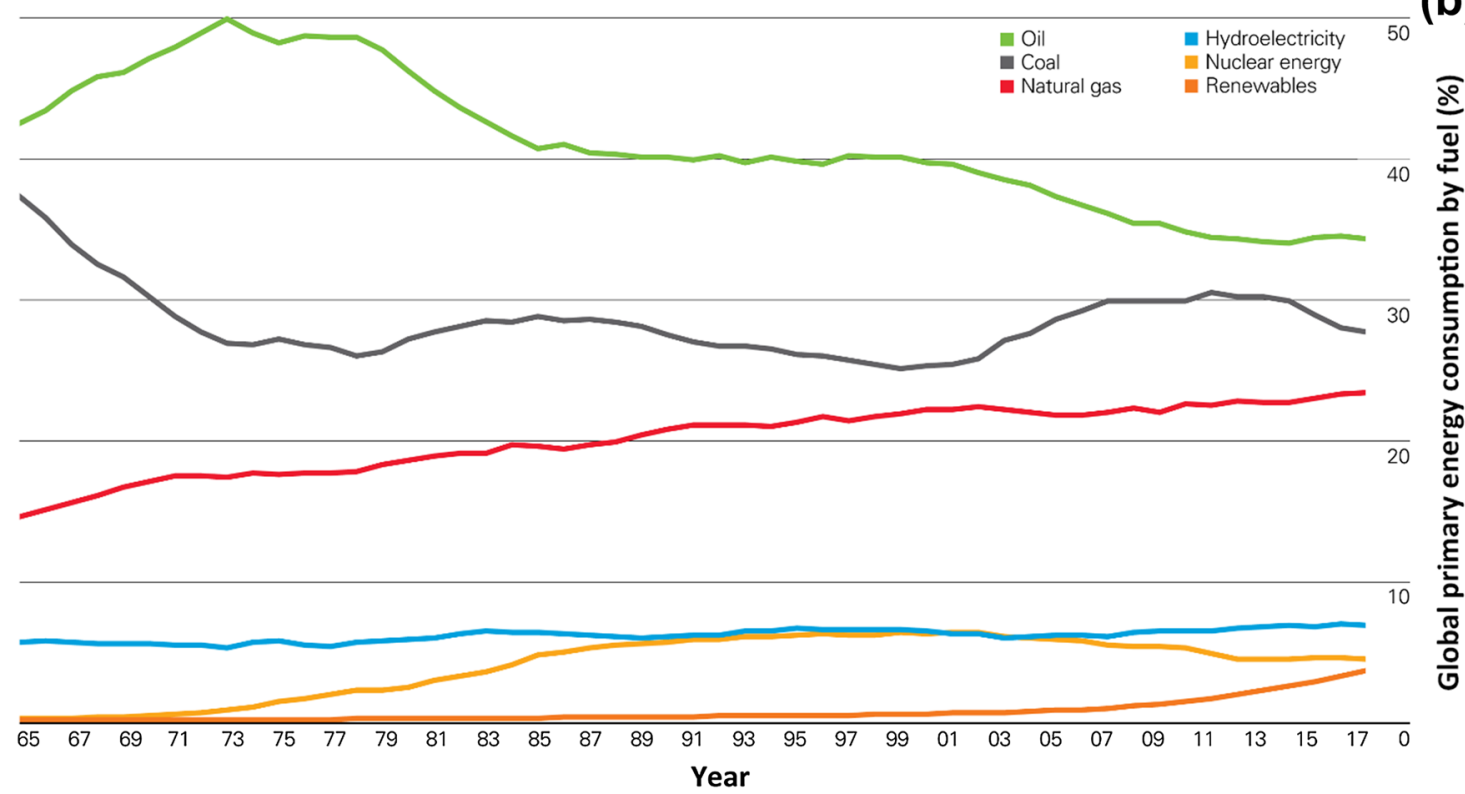

(b)

Fig. 1 a Global electricity generation by fuel (\%) (BP 2018b), and b global primary energy consumption by fuel (\%) (BP 2018b)

year) of global coal is 134, which is significantly higher than those of oil (50.2) and natural gas (52.6) (BP 2018b). Therefore, coal has greater potential for sustainable mining and utilisation. The BP energy outlook (2018) reported that nearly $70 \%$ of the increase in primary energy will be utilised for electric power generation by 2040. Figure 2a indicates that coal will reserve the largest share (approximately 30\%) among energy resources for generation of electric power in 2040 (BP 2018a). The U.S. Energy Information Administration (EIA) has projected coal to remain a key component of the U.S. national electricity portfolio at least until 2040 and, in the absence of the Clean Power Plan, coal production in the U.S. is likely to increase from 740 million short tons (MMst) in 2016 to $861 \mathrm{MMst}$ by 2040 (EIA 2017; Giam et al. 2018). Recently, a few countries have attempted to shift from utilising conventional energy sources to adopting renewable resources (IEA 2018a). However, the International Energy Agency (IEA) forecasts that the share of renewables in the total energy consumption will only be $18 \%$ by 2040 (IEA 2018a). According to the global energy outlook of the IEA, BP, and EIA, by 2040 , coal consumption will be broadly stable, 
(a)

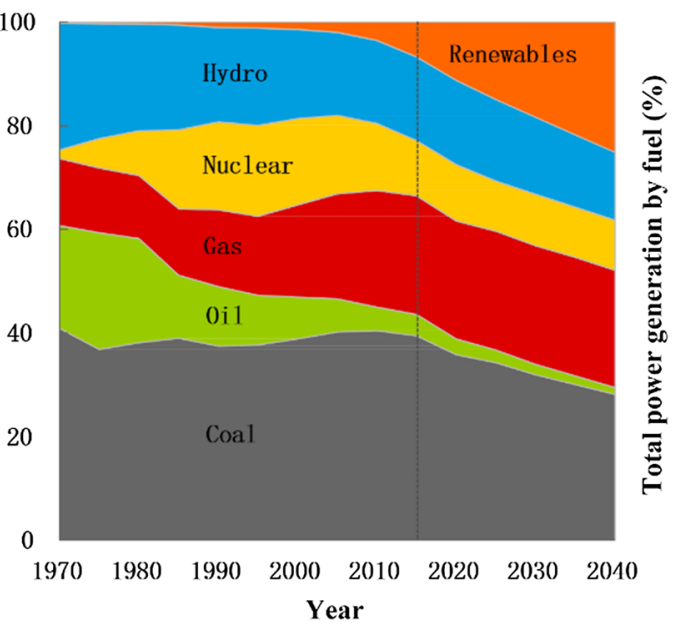

(b)

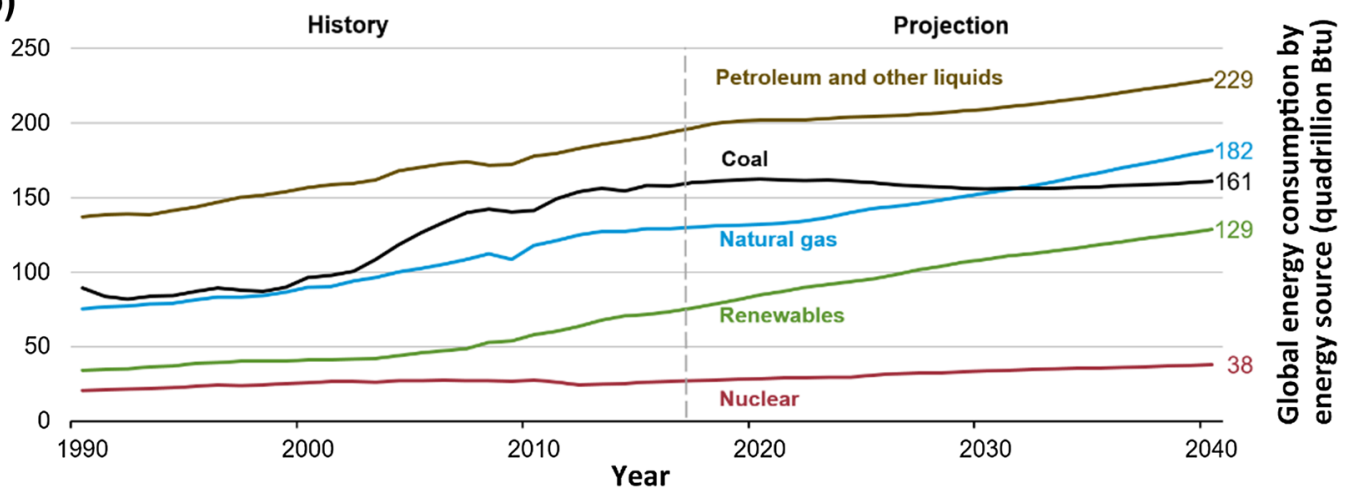

Fig. 2 a Total power generation by fuel (\%) (BP 2018a), and b global energy consumption by energy source (quadrillion Btu) (EIA 2018)

with a share of about a quarter in primary energy (Fig. 2b) (BP 2018a; EIA 2018; IEA 2018b). Therefore, coal is likely to continue to be the principal global energy source over the next few decades and achieving sustainable mining and clean utilisation of coal is imperative for further development of coal science and technology.

Unfortunately, traditional coal mining methods significantly contribute to pollution and are detrimental to the environment. Traditional coal mining and utilisation patterns release substantial quantities of $\mathrm{CO}_{2}, \mathrm{CH}_{4}, \mathrm{CO}$, mercury, sulphur and nitrogen oxides, organic compounds, and particulate pollutants (e.g. coal ashes and dust) (Fugiel et al. 2017; Gu et al. 2016; Peng et al. 2018; Restrepo et al. 2015). According to the IEA, carbon emissions from the production and utilisation of coal accounted for $44 \%$ of the total global carbon emissions in 2011, and this trend is likely to continue over the next 30 years (Aguirre-Villegas and Benson 2017; IEA 2016). Additionally, the $\mathrm{CH}_{4}$ discharged from coal combustion contributes to the greenhouse effect (Bloom et al. 2016). According to the U.S. Environmental Protection Agency (EPA) report released in 2016, coal mining produced $8 \%$ of the global anthropogenic $\mathrm{CH}_{4}$ emissions in 2010 , and this figure is expected to increase to 33\% by 2030 (EPA 2016; Xu et al. 2017). Meanwhile, solid wastes produced by traditional coal mining methods are also a significant source of environmental pollution (Liu and Liu 2010). The various solid wastes not only occupy significant land resources but also release toxic substances that contaminate the ambient soils and groundwater (Bian et al. 2012; Wu et al. 2017). Moreover, surface subsidence occurs during coal mining (Australian Government: Department of the Environment 2014) which causes abnormal changes in the surface water and underground hydrogeological status. Additionally, it significantly negatively influences the surface railway and road traffic, building safety, and environmental quality (Ghabraie et al. 2017; Wright et al. 2015). Moreover, traditional coal mining methods are highly likely to cause hazardous mining accidents (Chen et al. 2012; Ranjith et al. 2017). Safety during coal production significantly affects the health of the society and sustainable development of the economy (Zhang et al. 2016). Overall, the high carbon emissions, environmental pollution, surface subsidence, resource wastage, and frequent mining accidents caused by 
traditional coal mining and utilisation patterns seriously impede sustainable development of the economy and societies as well as the sustainable utilisation of coal resources (Chabukdhara and Singh 2016; Energy Reform Institute NDRC.P.R.C et al. 2019).

Therefore, it is imperative to explore new theories and technologies that ensure high safety, low environmental pollution, and low formation damage during coal mining. Furthermore, it is essential to develop safe and low-carbon mining technologies for clean utilisation of coal resources and sustainable economic development. To achieve the goal, we recently proposed a novel idea for in situ fluidized mining of underground coal, that is, transforming deep solid coal into gaseous, liquid, or gas-solid-liquid mixedstate substances in situ (Xie et al. 2017a, b). This idea provides a potential solution to various environmental problems, such as surface subsidence, high carbon emissions, large $\mathrm{CH}_{4}$ outrush, high pollution, high energy consumption, and severe waste of resources, arising from traditional mining patterns. To make the idea a reality, in this study, we designed a new flexible unmanned automatic mining machine (UAMM), like an earthworm, and specify a coal mine layout for deep in situ fluidized mining suited to the UAMM. The UAMM-based mining method integrates excavation and support of the vertical shaft and roadways, coal mining, coal separation, gangue disposal, in situ coal conversion, in situ waste purification and remedy, storage of fluidized energy resource and electrical energy, highly-efficient transportation, and goaf filling in a single mining practice. In particular, coal and solid wastes are not transported to the ground. The raw coal as well as the $\mathrm{CH}_{4}$ and $\mathrm{CO}_{2}$ released during coal mining are transformed into a clean energy source in situ. This design is expected to achieve sustainable, safe, and environmentally friendly coal mining, as well as low-carbon and clean utilisation of coal to adhere to the "no coal on the ground, and no men in the coal mine' practise. This study also compared the proposed technology with traditional coal mining methods to assess the technological and economic advantages and the carbon emission reduction of in situ fluidized mining of deep coal. The development trends and main limitations of this approach were also reported.

\section{Structure and functions of the UAMM}

\subsection{General design}

As indicated in Fig. 3, the UAMM was designed to adopt an earthworm-like structure that could be disassembled and re-assembled to accommodate the differences between roadway tunnelling and coal seam mining. Figure $3 \mathrm{a}$ demonstrates the UAMM-T (tunnelling) which is used in excavation of vertical shafts and rock roadways, Fig. 3b indicates the UAMM-M (mining) used in coal seam mining, and Fig. 3c presents the top view of the UAMM-M, which is characterised by a worm-like free bending structure. Both UAMM types consist of multiple functional modules (with polygonal cross-sections of equal or unequal sides) to meet the needs of independent operations and tunnelling. The functional modules are connected by detachable flexible components which allow turning as well as up-slope and down-slope movements along the inclined coal seams during excavation. Different functional modules are linked by these flexible components to create the UAMM-T (suitable for tunnelling) or the UAMM-M (suitable for coal seam mining).

Intelligent and unmanned mining of deep coal seams requires the construction of a wireless remote-control platform on the ground to manage and monitor the operation and work state of the UAMM. A motorized drive is installed in each functional module of the UAMM, which allows the module to independently move forward or backward according to the instructions received from the remote monitoring platform. The flexible components of the UAMM were manufactured using high-strength and high-toughness materials to ensure secure connections between the functional modules. This also allows the UAMM to adjust its track readily for making turns, climbing uphill, and going downhill, thus facilitating its adaptation to complex terrain structures and occurrences of coal.

\subsection{Structure and functions of the UAMM-T}

The UAMM-T used for roadway tunnelling primarily consists of a mining module (equipped with a cutter-head and a microwave radiation device) and a supporting module (Fig. 3a). The mining module is primarily used for rock breaking and excavating. Additionally, its rear is fitted with an anchor drilling rig to provide preliminary support during shaft and roadway tunnelling. As shown in Fig. 3, the UAMM-T and UAMM-M heads are equipped with microwave radiation devices to break the rock or coal with microwave radiation, as well as cutter-heads for mechanical cutting; thus, improving the efficiency of hard rock or hard coal seam drilling. Hong et al. (2016) reported that microwave pre-treatment increases the number of microcracks in coal and rock, as well as the degree of cracking to facilitate fragmentation. Hassani et al. (2016) studied the influence of microwave radiation on the strength of the rock and utilised microwave radiation in a tunnel boring machine (TBM) to aid mechanical rock breaking. Similarly, the UAMM uses microwave radiation to reduce the strength of coal and the rock located in front of it, and it simultaneously performs mechanical cutting with the 
(a)

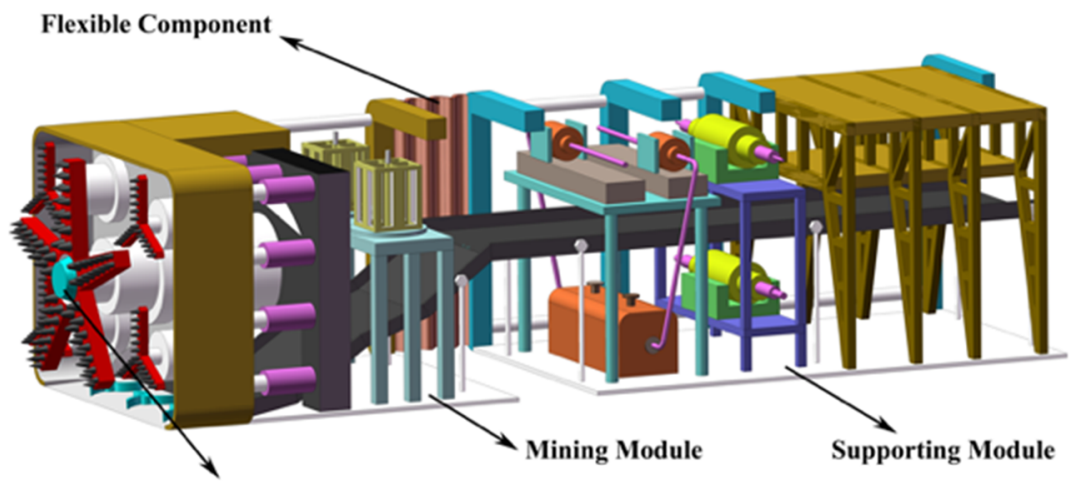

Microwave Radiation Device

(b)

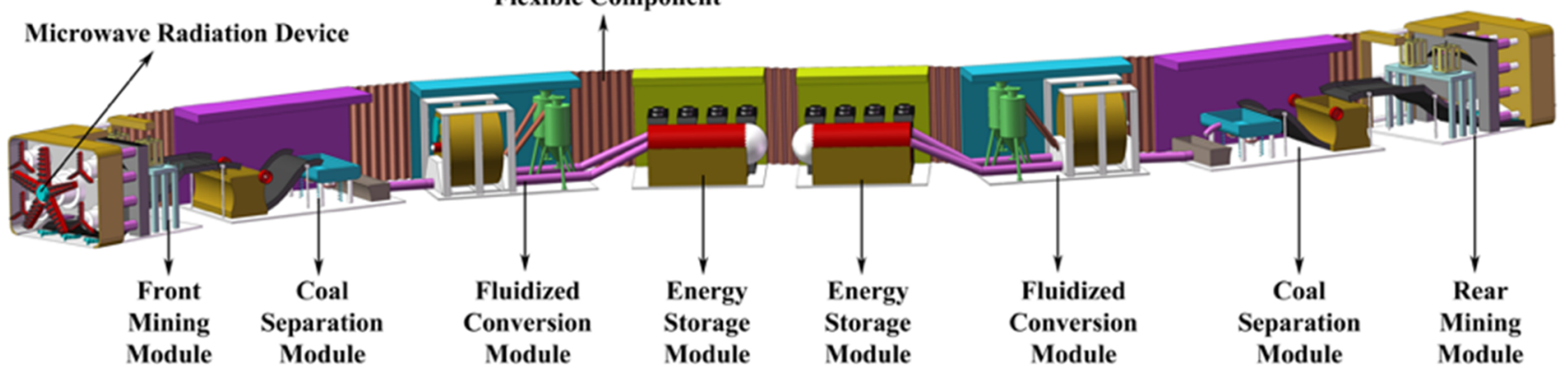

(c)

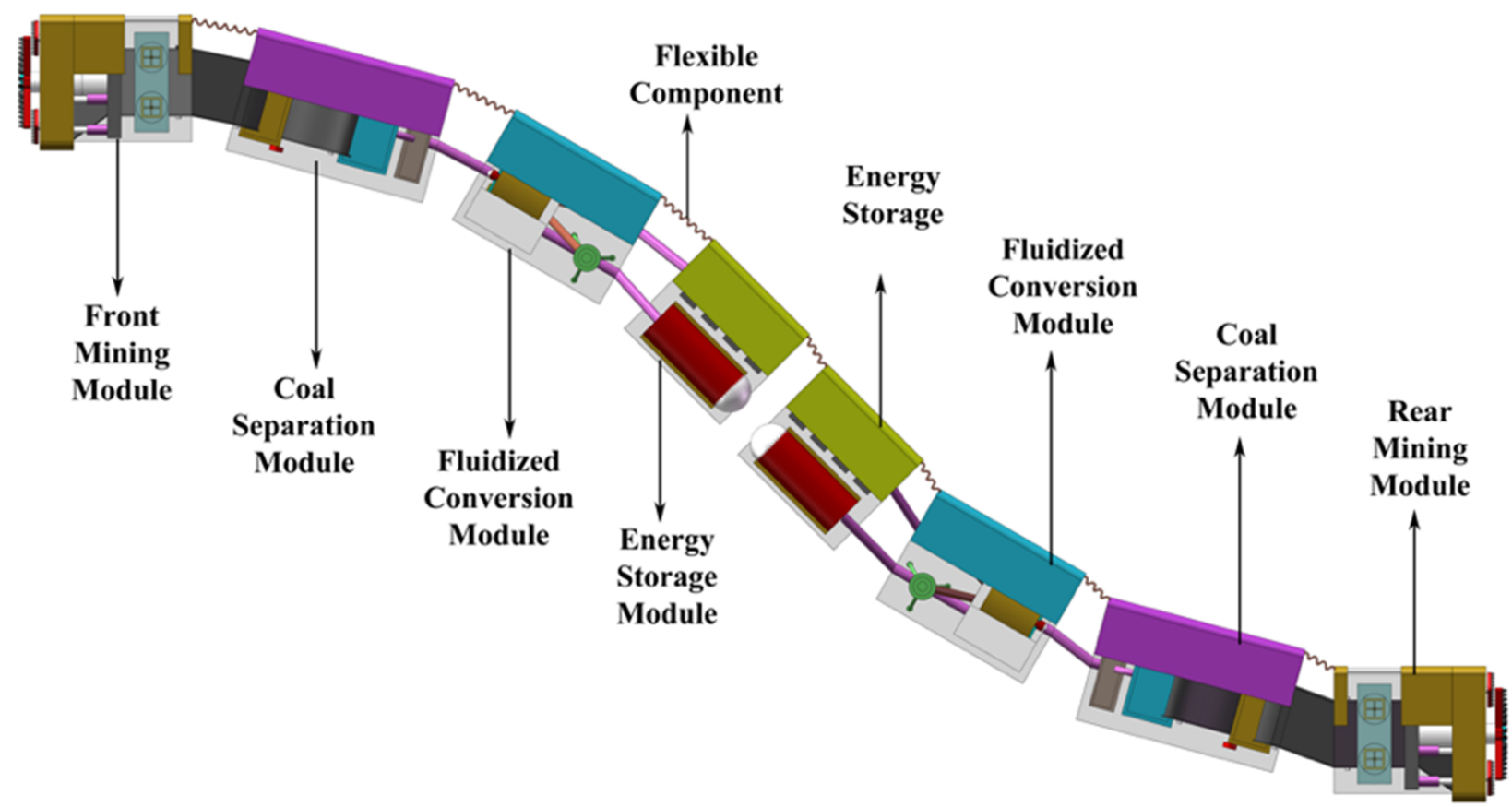

Fig. 3 Schematic of the UAMM and its components: a UAMM-T, b front view of the UAMM-M, and $\mathbf{c}$ top view of the UAMM-M

cutter-head. Thus, the excavation efficiency through rock layers or coal seams is significantly improved. The supporting module essentially functions to support the surrounding rocks in the shaft and the roadway. A fully digitized and computerized control system is used to ensure different forms of support (chemical grouting, placing 
segmental linings, etc.) for the surrounding rocks. Gas extraction equipment is installed in the supporting module to reduce the risk of coal-gas outburst by extracting gas from both sides of the coal seam while the roadway undergoes excavation. Moreover, chemical grouting equipment (in addition to bolts in the mining module) is also present in the supporting module for reinforcement and to ensure stability of the shaft and roadway. A special chemical slurry can be injected on both sides of the roadway coal seam to reinforce the wall. Lining fabrication and installation equipment in the supporting module can be subsequently used to construct permanent high-strength lining supports for the excavated vertical shaft and roadway.

\subsection{Structure and functions of the UAMM-M}

The UAMM-M used for coal seam mining is made of symmetrical front and back halves. The front half consists of, from front to rear, the mining, coal separation, fluidized conversion, and energy storage modules. The back half is a mirror image of the front half (Fig. 3b, c). The structure and functions of the UAMM-M mining module are same as those of the UAMM-T. Coal and gangue are automatically fragmented and separated by a crusher and a motorized jigger sieve in the coal separation module. The gangues are subsequently removed from the module through the side pipe and used as aggregate for backfilling of the goaf. A set of fluidized conversion instruments is built into the fluidized conversion module to transform the separated solid coal into gaseous, liquid, or mixed gas/solid/liquid energy sources or into electricity through fluidized conversions such as physical crushing, chemical conversion, biodegradation, and electricity generation by pulverized coal deflagration (Xie et al. 2017a, b, 2018a, b). Some of this energy is utilised to power the UAMM-M, while the rest is stored in the fluidic product and the energy storage unit of the storage module and is subsequently collectively transported to the ground surface through pipelines. A set of waste purification devices, which utilise reactive materials to treat and convert the wastes of fluidized conversion, are also provided in the fluidized conversion module. The fluidized conversion devices emit significantly lower quantities of $\mathrm{CO}_{2}$ and $\mathrm{CH}_{4}$ during liquefaction or gasification of solid coal, thus alleviating high pollution, high energy consumption, and significant resource wastage. Additionally, solid wastes generated from mining, such as gangue and residues, are not hoisted to the ground (in contrast to traditional mining) but are re-used as aggregates during in situ backfilling of the underground goaf. This practice can reduce transportation and hoisting costs and alleviate contamination of the ground surface environment by toxic solid wastes, thus accomplishing safe in situ processing of wastes such as gangue and slag.

\section{In-situ fluidized mining based on the UAMM}

\subsection{Layout and construction}

The production line in traditional mining includes coal hauling, ventilation, material and gangue transportation, and drainage systems. Significant work is necessary for the excavation of roadways, and the costs of constructing and maintaining roadways and shafts are high. Numerous coal pillars need to be placed in the mine, and the coal recovery rate is inefficient. The extracted coal is subsequently transported to the ground surface for washing before utilisation and involves high transportation and hoisting costs as well as pollution of the environment. Therefore, in this study, a coal mine layout was planned for in situ fluidized mining based on the UAMM to maximise the potential of the UAMM, reduce the work load for excavation of roadways, reduce resource wastage, lower the coal transportation and hoisting costs, and eliminate environmental pollution.

Figure 4 shows a 3-D schematic of the coal mine layout for in situ fluidized mining based on the UAMM. The entire mining field was regarded as an approximately quadrilateral mining area in this layout. The bottom parts of the main shaft and air shaft are located diagonally in the mining field, in the shallow and deep coal seams, respectively.

The underground chambers near the main shaft and air shaft (excavated using the UAMM-T) are excavated and constructed by a rock-drilling robot (Fig. 4) (Babjak et al. 2016). The mining and supporting modules are first connected and assembled into the UAMM-T on the ground using the flexible components (Fig. 3a). The UAMM-T is lifted and pulled into a vertical position for excavating the main shaft and air shaft by utilising the hoisting and traction equipment. Once excavation reaches the coal seam, the UAMM-T is placed into a horizontal position by the assembly robots (Pan et al. 2018). Subsequently, the UAMM-T tunnels four main roadways along the boundary of the mining field and several crossheadings which run across the interior of the mining field in accordance with the inclination of the coal seam (Fig. 4). The UAMM-T also provides comprehensive, high-strength support for vertical shafts and roadways during excavation.

Additionally, the gas extraction equipment in the supporting module can extract gas from the coal seam (on both sides of the roadway) during excavation to prevent potential gas explosions or coal-gas outbursts. The extracted gas is then transported to the underground gas power station 


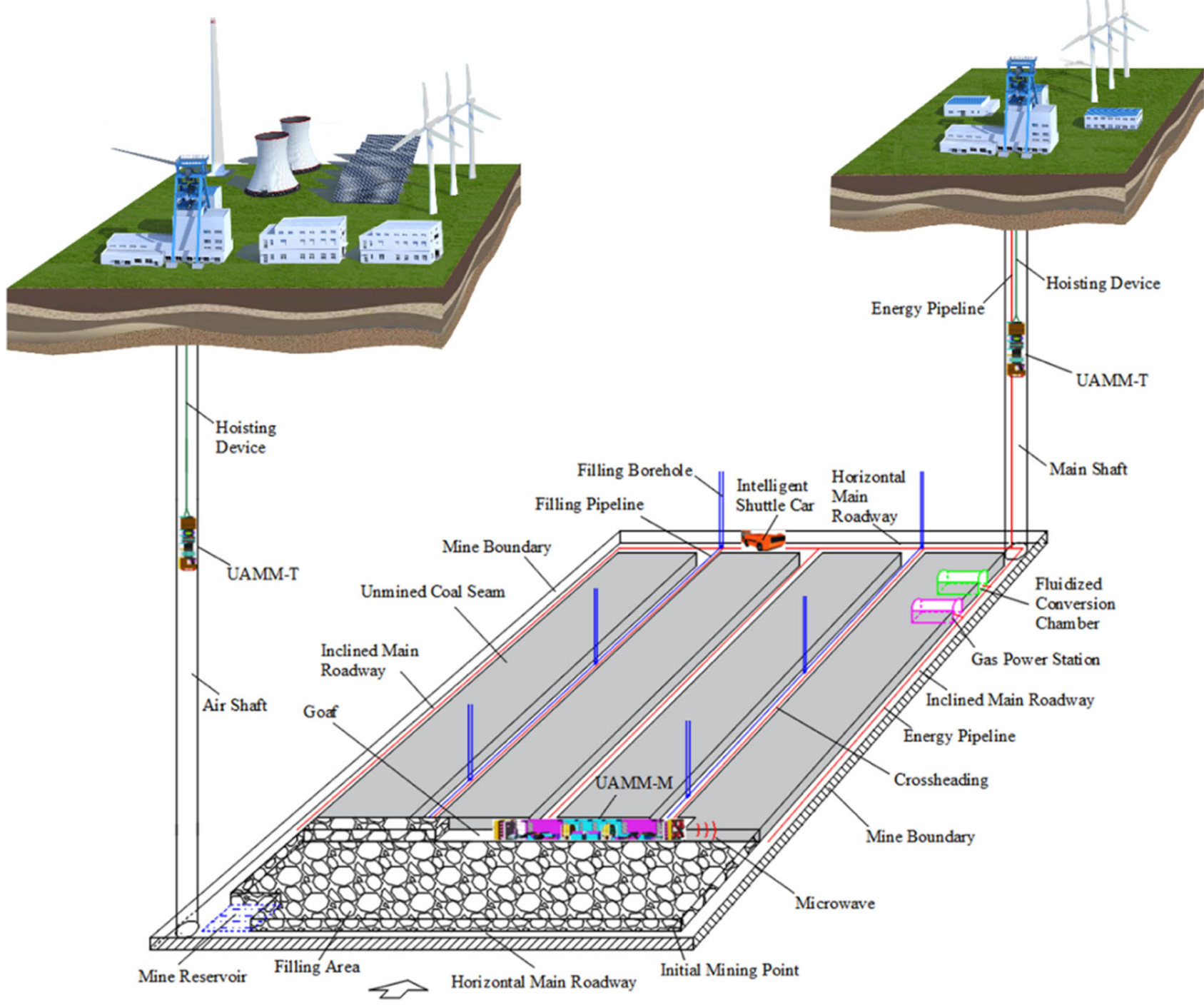

Fig. 4 Schematic of the coal mine layout for UAMM-based in situ fluidized mining

(Fig. 4) via the energy transmission pipelines embedded in the roadways for power generation. The electricity is subsequently transmitted to the ground through energy transmission pipelines in the main shaft. The coal and gangue broken by the cutter-head during excavation are sent to the rear of the supporting module through a conveyor belt and are discharged and transported to the fluidized conversion chamber via underground intelligent shuttle cars (Fig. 4). The sorted coal is transformed into fluidized energy sources and electricity in the fluidized conversion chamber. These products are also transported to the ground through energy transmission pipelines in the main shaft. The sorted gangues are raised to the ground via the main shaft for subsequent backfilling of the goaf. The anchor drilling rigs in the supporting module are used to support the interior of the vertical shafts and roadways during excavation. Additionally, the chemical grouting equipment in the supporting module injects a special chemical slurry into coal seams on both sides of the roadway to reinforce the walls. Furthermore, the lining installation equipment installs all-around, high-strength lining supports for the excavated vertical shafts and roadways to ensure long-term stability at these locations.

\subsection{In-situ fluidized mining}

The UAMM-T is dissembled underground by the assembly robots after the mine is constructed. Subsequently, the mining and supporting modules are separated. The latter is lifted above ground, whereas the former is left underground for use as the front and rear mining modules of the UAMM-M. The coal separation, fluidized conversion, and energy storage modules, as well as the necessary flexible components of the UAMM-M, are transferred 
underground. The functional modules are connected and assembled by the assembly robots using the flexible components according to the UAMM-M structure shown in Fig. 3b. The completed machine is subsequently used for two-direction (both forward and backward directions) coal mining (Fig. 4). Mining is initiated at the corner of the mining field in the deep coal seam, adjacent to the corner with the main shaft bottom. One mining cycle includes two strip-shaped routes along the strike of the coal seam for forward and backward coal mining. Since the UAMM-M is of considerable length with a large turning radius, a special route-changing scheme was developed to allow switching between the forward and backward mining modes (Fig. 5). The UAMM-M first performs forward mining in a straight line and retreats a certain distance along the original lane after reaching the mine boundary (Fig. 5a-c). Subsequently, it switches lanes and moves forward again (Fig. 5d), with its forward mining module reaching the mine boundary as it finishes switching lanes (Fig. 5e). Once the lane switching is complete, the machine travels to the next mine boundary in a straight line in the reverse direction while continuing to mine (Fig. 5f) and move forward using the same lane-switching technique.

The coal and gangue mined by the mining module are transported to the coal separation module by a conveyor belt for subsequent crushing and sorting. The sorted gangues are discharged through the side pipe and stored in the goaf as aggregates for backfilling, whereas the sorted coal is transported to the fluidized conversion module. The sorted solid coal is converted to gaseous, liquid, or mixed gas/solid/liquid fluidized energy sources or electricity by the fluidization transformation technique. Additionally, waste purification devices are used to ensure generation of hazard-free waste. The treated solid wastes are discharged and stored in the goaf as aggregates for subsequent backfilling. A small portion of the fluidized energy sources or the electricity generated from the fluidized conversion module is utilised to power the UAMM-M, whereas the remainder is temporarily stored in the energy storage module. The UAMM-M passes several inclined main roadways and crossheadings perpendicular to the 'strip' routes during mining to connect with the embedded energy transmission pipelines. The fluidized energy and electricity resources are transmitted to the ground, whereas resources essential for the operation of the UAMM-M (such as water) are transported back.

Anchor drilling rigs in the mining module of the UAMM-M, which support the coal seam roof, as well as backfilling of the strip-shaped goaf are utilised to prevent collapse of the strata above the goaf and reduce surface subsidence. As shown in Fig. 6, a filling wall is constructed behind the UAMM-M after coal mining has been performed for a certain distance. This filling wall separates the

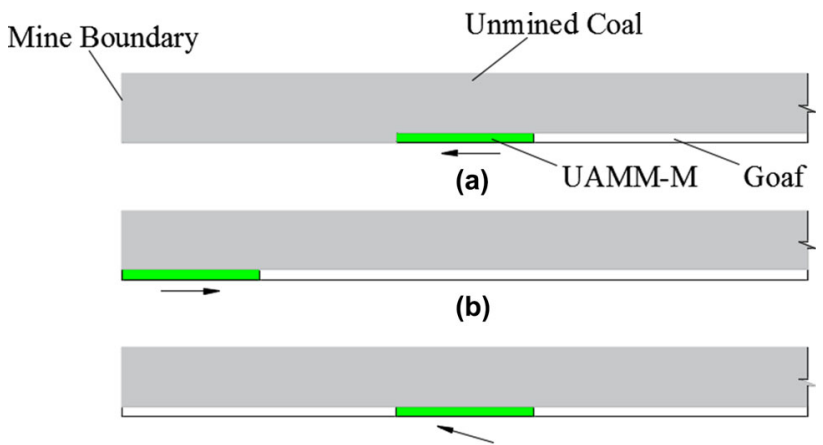

(c)

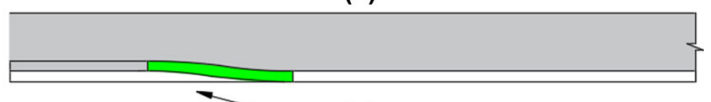

(d)

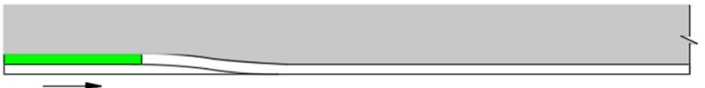

(e)

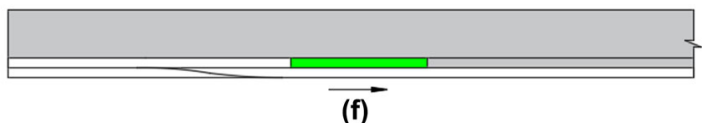

Fig. 5 Lane-switching procedure during two-direction coal mining by the UAMM

UAMM-M from the strip-shaped goaf at its rear as well as the filling slurry. The filling walls are also placed at the entrances of crossheadings along the mining route to prevent the filling slurry from flowing into the crossheadings. Once the filling walls are constructed, the filling slurry is transported from the surface to underground via the vertical filling borehole (Fig. 4) and to the goaf via the filling pipelines. The slurry is mixed with gangue (removed during coal washing) and the residue from the fluidized conversion module to refill the goaf, thus forming the filling area.

\section{Estimation of costs of UAMM-based in situ fluidized mining}

The cost of mining is an important consideration for application of the UAMM-based deep in situ fluidized mining technique. Estimation of costs includes the various expenses incurred by enterprises during the production of coal products. Currently, the cost of raw coal is assigned as the production cost; therefore, the total cost of a coal product comprises the production cost and other costs incurred during that period. This total cost is divided by the output of raw coal to yield the unit cost of raw coal, i.e. cost of coal per ton (Zhang and Xu 2007). The unit cost of raw coal obtained by this method is known as the "conventional coal cost per ton'. However, this cost computation is not all-inclusive because costs related to other 


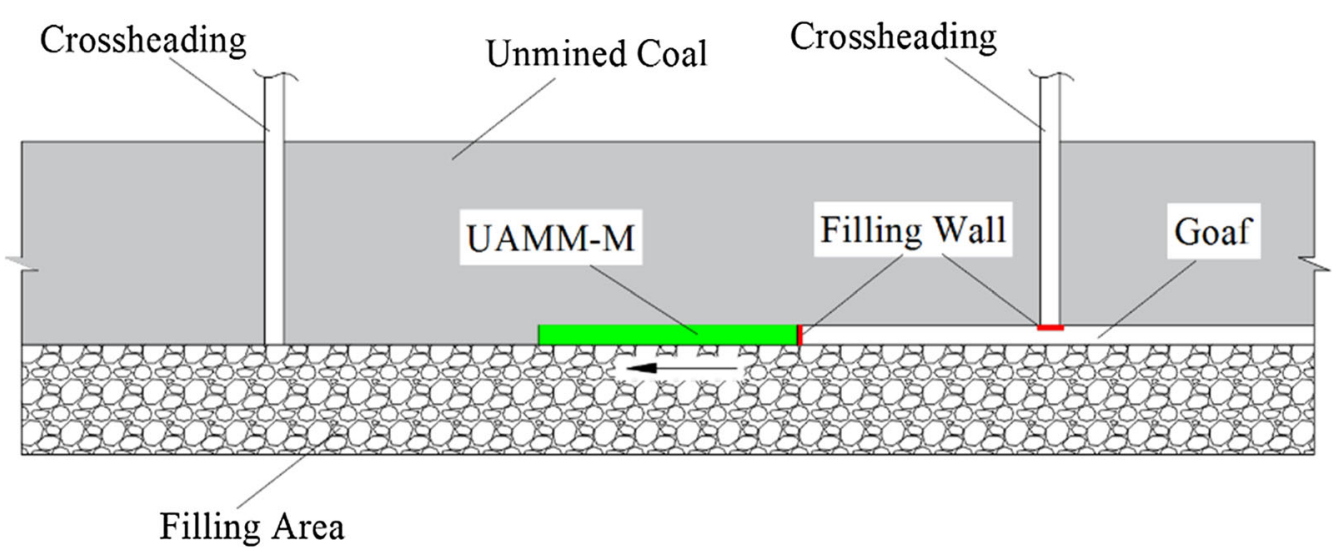

Fig. 6 Top view of the filling wall project for UAMM-based in situ fluidized mining

aspects, such as wastage of coal resources in traditional mining (attributed to the protective coal pillars remaining, top coal caving, etc.) and environmental pollution caused by post-mining transportation and utilisation, which directly impact the transparency and accuracy of coal cost calculation, are not reflected. The average recovery rate of coal resources through traditional mining methods is less than $40 \%$ in China (Wang 2007). The cost of coal per ton for a coal mine adopting traditional mining methods and located at a depth of $\sim 600-800 \mathrm{~m}$ in eastern Henan Province, China was reported to be at least 2.8 times the conventional coal cost per ton estimated by the current method. This could be attributed to economic losses due to wastage of coal in the traditional mining methods.

The environmental costs of coal utilisation must be estimated considering the goal of sustainable development of natural resources, the economy, and the environment. Coal-fired power generation has been shown to cause significant environmental pollution in China, which translates to high environmental costs of coal utilisation. The environmental cost of power generation by coal indicates the environmental damage not reflected in the market price. The environmental costs of electricity generation can be estimated by the external costs of energy (ExternE) method of the EU which is based on the value of social damage caused by pollutants (Krewitt and Nitsch 2003). The pollutants considered in the calculation of environmental costs are $\mathrm{PM}_{10}, \mathrm{SO}_{2}$, and $\mathrm{NO}_{x}$ haze particles as well as the $\mathrm{CO}_{2}$ produced during power generation (El-Kordy et al. 2002; Vrhovcak et al. 2005). Presently, the sulphur content of coal used for power generation in China is $1 \%$, while the ash content of raw coal is $28 \%$. The efficiency of electrostatic precipitation has been reported as $99 \%$, and the desulphurization efficiency for environmental protection is 95\% (Ding et al. 2007). The annual consumption of coal in a coal-fired power plant with an installed capacity of $500 \mathrm{MW}$ and an annual utilisation time of $6000 \mathrm{~h}$ is 1.341 million tons. The environmental cost of this power plant, as estimated by the ExternE method, is 386.8 Renminbi (RMB) per ton of coal. The cost of coal per ton for the same coal mine located at a depth of $\sim 600-800 \mathrm{~m}$ is likely to be twice the estimated environmental cost.

Thus, the cost of coal per ton for traditional mining (after considering wastage of coal resources and environmental costs) is 3.8 times higher than that computed for the present method. However, if the 'comprehensive cost of coal per ton' is defined as the coal cost per ton including wastage of coal resources and the environmental costs, then the value is at least 4.8 times the conventional coal cost per ton. Therefore, the UAMM-based in situ fluidized mining of deep coal significantly enhances the exploitation efficiency of resources, reduces waste generation, and achieves a near-zero loss of coal resources. It also discharges almost no pollutants during coal mining, transportation, and utilisation. Therefore, the UAMM-based mining technology provides cost savings equivalent to nearly four times the conventional coal cost per ton.

UAMM-based mining is currently not practised in rock and coal seam exploitation; therefore, excavation costs of UAMM-based mining were estimated using the TBM costs as reference. The latter has been used in several coal mines in China to tunnel inclined shafts, adits, and roadways and has several structural and functional similarities with the UAMM. The excavation of an inclined shaft by the TBM in a coal mine in western China utilised a cutter-head with a diameter of $7620 \mathrm{~mm}$ and produced 63.85 tons of coal per meter advanced (for a coal density of $1.4 \mathrm{~g} / \mathrm{cm}^{3}$ ). The estimated comprehensive mining cost per ton of coal was 892.7 RMB, which was 2.38 times the conventional coal cost per ton. These costs were significantly less than the comprehensive coal cost per ton for traditional mining.

Therefore, these results indicate that the comprehensive coal cost per ton for traditional mining is 4.8 times the conventional coal cost per ton. In contrast, the 
comprehensive coal cost per ton for UAMM-based in situ fluidized mining is only 2.38 times the conventional coal cost per ton and approximately $49 \%$ lower than the comprehensive coal cost per ton for traditional mining. Thus, UAMM-based in situ fluidized mining reduces the exploitation and utilisation costs of deep coal mining and realizes near-zero loss of coal resources, clean utilisation of coal, near-zero emission of pollutants, and sustainable development. Thus, this technique is likely to offer substantial socio-economic benefits.

\section{Carbon emissions of UAMM-based in situ fluidized mining}

As an important source of anthropogenic $\mathrm{CO}_{2}$ emissions, power plants account for more than $40 \%$ of global anthropogenic $\mathrm{CO}_{2}$ emissions (Yu et al. 2014). According to the China Electricity Council (CEC), more than 99\% of China's thermal power is derived from the coal-fired thermal power group (CEC 2012). Thus, coal-fired power generation is the largest source of carbon emissions in China (Yu et al. 2014). Moreover, the improvement in residents' living standards and the growth of the population are expected to lead to an increase in global demand for electricity consumption. Therefore, in the context of global warming, determining how to reduce carbon emissions from the coal power industry will become the focus of global attention, especially for the Chinese government (Yu et al. 2014).

Life cycle assessment (LCA) is a valuable tool for providing a comprehensive 'cradle-to-grave' view of the environmental burdens of a technology. LCA is often used to analyse renewable energy alternatives to conventional energy systems, especially for estimating greenhouse gas (GHG) emissions (Hsu et al. 2012). Over the past two decades, energy analyses of electricity generation systems using LCA have been extensively conducted worldwide
(Nishimura et al. 2010; Jing et al. 2012; Gonzalez-Garcia et al. 2012).

For coal-fired power generation, the carbon emissions of coal resources based on LCA include the total carbon emissions generated during the mining, washing, transportation, and combustion of coal resources. Yu et al. (2014) utilised LCA to assess the effect of carbon emissions and to calculate the coefficient of carbon emissions in coal-to-energy chains. According to the measurement model of carbon emissions in a coal-energy chain, the main GHG emissions of different processes can be calculated by using the normalized $\mathrm{CO}_{2}$ equivalent, thereby obtaining the total carbon factor. Results shown that the carbon emissions from $1 \mathrm{~kW} / \mathrm{h}$ of coal-fired electricity generation caused in the process of coal mining, selecting and washing, transportation, and electricity generation were $43.79 \mathrm{~g}$, $0.32 \mathrm{~g}, 9.92 \mathrm{~g}$, and $821.13 \mathrm{~g}$, respectively. The $\mathrm{CO}_{2}$ emission coefficient of the coal-to-energy chain in China is $875.16 \mathrm{~g} / \mathrm{kW} \mathrm{h}^{-1}$. As shown in Fig. 7, the emissions of the power generation process account for $93.8 \%$ of the total emissions in the whole chain, thus being the largest contributor.

The UAMM-based mining method converted coal resources into fluidized energy and electricity resources in situ. GHG generated in the process of coal conversion into electricity is directly captured and stored in the deep goaf and will not be discharged into the atmosphere. Therefore, the carbon emissions of $1 \mathrm{~kW} / \mathrm{h}$ of coal-fired electricity generation caused in the process of coal transportation and the processes of coal-fired power plants is zero. Moreover, external power sources are needed during coal mine construction, while the energy required by UAMM in the process of coal mining and washing comes from the electricity generated by its own coal-fired power generation. GHG generated by UAMM's own power generation is also not discharged into the atmosphere. Thus, the GHG generated by the UAMM-based mining method in the process of coal mining and washing is much smaller

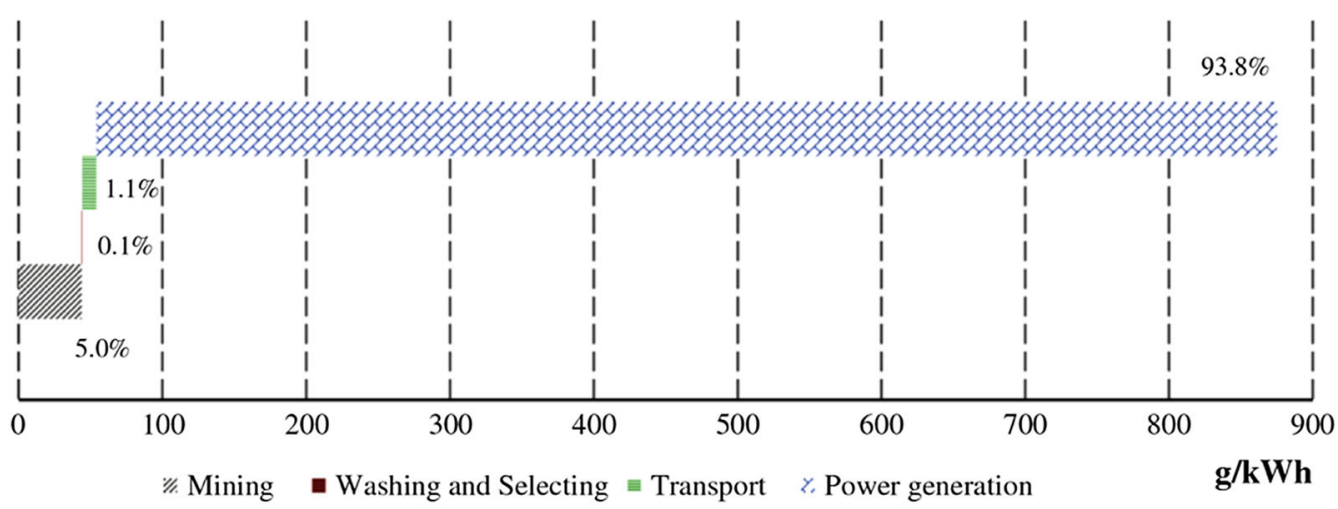

Fig. 7 Proportion of $\mathrm{CO}_{2}$ emissions of various processes in the coal-to-power energy chain (Yu et al. 2014) 
than that produced by traditional mining methods. Therefore, compared with traditional coal mining methods, UAMM-based in situ fluidized mining can reduce $\mathrm{CO}_{2}$ emissions by at least $94.9 \%$.

In 2010, the coal-fired power generating capacity of China was 3.4166 trillion $\mathrm{kW} / \mathrm{h}$, and the estimated total $\mathrm{CO}_{2}$ emissions from the coal-to-energy chain was roughly 2.99 billion tonnes. The $\mathrm{CO}_{2}$ emission from coal mining was 149.60 million tonnes. The $\mathrm{CO}_{2}$ emission from coal transportation was 33.90 million tonnes, whereas that from coal combustion in plants was 2.81 billion tonnes (Yu et al. 2014). Therefore, taking the coal-fired power generation in China in 2010 as an example, UAMM-based in situ fluidized mining can reduce $\mathrm{CO}_{2}$ emissions by at least 2.84 billion tonnes.

Therefore, UAMM-based in situ fluidized mining is conducive to the development of a clean, low-carbon, safe, environmentally friendly, and efficient energy system in China and the realization of decarbonisation of the economy in the EU.

\section{Conclusions}

This study introduced the UAMM and proposed a coal mine layout and coal mining method for in situ fluidized mining based on the UAMM. These designs provide a novel solution for issues that impede the 'zero environmental pollution mining' of deep coal resources. The UAMM-based method proposed in this study integrates excavation and support of vertical shafts and roadways, mining and separation of coal, treatment of gangues, in situ conversion of coal, in situ purification and processing of waste, storage of fluidized energy and electricity resources, high-efficiency transportation, and goaf filling in a single mining practise. In contrast to traditional mining methods, the UAMM-based mining method employs a simple roadway layout that avoids the construction of large roadways, uphill and downhill roadways, adits, and crosscuts. Moreover, this method helps reduce the costs associated with roadway excavation and maintenance as well as transportation and hoisting of coal. The proposed method also improves the mining, transportation, conversion, and utilisation efficiency of coal, reduces resource wastage, and cuts production costs. The adoption of this method mitigates or prevents high-risk underground accidents associated with traditional coal mining such as roof falling, gas outburst, gas explosion, coal-dust explosion, floods, and fire. This method also helps address environmental and energy issues related to surface subsidence, high $\mathrm{CO}_{2}$ and $\mathrm{CH}_{4}$ emissions, high pollution and energy consumption, and significant resource wastage. In particular, this mining technique allows excavation of roadways and coal mining at high-temperature underground conditions. This could potentially save manpower and even reduce casualties.

It is estimated that the total cost of UAMM-based fluidized coal mining is approximately $49 \%$ of the traditional coal mining costs. This is attributed to cost reductions due to minimal resource losses, reductions in emissions and energy consumption, disaster prevention, and environmental protection. Moreover, compared with traditional coal mining methods, UAMM-based in situ fluidized mining can reduce $\mathrm{CO}_{2}$ emissions by at least $94.9 \%$.

In summary, the UAMM-based deep in situ fluidized mining method has significant advantages in terms of economizing resources, reducing carbon emissions, alleviating disasters, preventing casualties, protecting the environment, and ensuring sustainable development.

Notably, this preliminary study outlines the principles and potential applications of the UAMM-based in situ fluidized mining. Several fundamental theoretical and technical issues need to be further studied and resolved before implementation of this method in the industry. Future research in this regard should focus on: (1) establishing theories for deep in situ multi-physics coupling and multi-field rock mechanics, as well as developing a theoretical model and evaluation system for assessing the efficiency and disaster-causing possibility of UAMMbased mining; (2) developing a wireless remote-control platform for monitoring and manipulation of the operation state of the UAMM; (3) constructing a three-dimensional dynamic mine model, including a high-precision geological model, for 'transparent' in situ fluidized mining; (4) developing in-advance detection and automated riskavoidance systems for comprehensive, a priori detection of geological information, such as geological composition, distribution and composition of water and coal resources, and automated avoidance of detected geological disasters; (5) developing intelligent robots for rock excavation, construction of underground chambers, transportation of materials, and the assembly, maintenance, replacement, emergency repair, and rescue of the UAMM; (6) developing high-efficiency microwave-assisted rock-crushing technology as well as cutter-head and cutting tool materials; (7) researching and developing bolt, segment, and lining materials with high supporting strength and low cutting difficulty; (8) developing novel, efficient, and intelligent coal separation equipment; (9) developing efficient fluidized conversion technologies such as physical crushing, chemical conversion, biodegradation, and electricity generation through deflagration of pulverized coal; (10) developing treatment and conversion technologies for gaseous, liquid, and solid wastes; (11) developing highcapacity storage devices for fluidized products and energies; (12) developing technologies for continuous transportation of fluidized resources over long distances and 
significant depths; (13) establishing an environmental assessment and evaluation system for UAMM-based deep in situ mining. In summary, the industrial application of UAMM-based deep in situ fluidized mining is possible only after solutions to the above-mentioned theoretical and technical problems are determined.

Acknowledgements The authors gratefully acknowledge the financial support provided by the State Key Research Development Program of China (Grant Number 2016YFC0600705); the National Natural Science Foundation of China (Grant Numbers 51674251, 51727807, and 51374213); the National Major Project for Science and Technology (Grant Number 2017ZX05049003-006); and the Innovation Teams of Ten-thousand Talents Program sponsored by the Ministry of Science and Technology of China (Grant Number 2016RA4067).

\section{Compliance with ethical standards}

Conflict of interest The authors declare that they have no conflict of interests.

Open Access This article is distributed under the terms of the Creative Commons Attribution 4.0 International License (http://crea tivecommons.org/licenses/by/4.0/), which permits unrestricted use, distribution, and reproduction in any medium, provided you give appropriate credit to the original author(s) and the source, provide a link to the Creative Commons license, and indicate if changes were made.

\section{References}

Aguirre-Villegas HA, Benson CH (2017) Case history of environmental impacts of an Indonesian coal supply chain. J Clean Prod $157: 47-56$

Australian Government: Department of the Environment (2014) Background review: subsidence from coal mining activities

Babjak J, Novak P, Kot T, Moczulski W, Adamczyk M, Panfil W (2016) Control system of a mobile robot for coal mines. In: Proceedings of the 2016 17th international Carpathian control conference

Bian ZF, Miao XX, Lei SG, Chen SE, Wang WF, Struthers S (2012) The challenges of reusing mining and mineral-processing wastes. Science 337(6095):702-703

Bloom AA, Lauvaux T, Worden J, Yadav V, Duren R, Sander SP, Schimel DS (2016) What are the greenhouse gas observing system requirements for reducing fundamental biogeochemical process uncertainty? Amazon wetland $\mathrm{CH} 4$ emissions as a case study. Atmos Chem Phys 16(23):15199-15218

BP (2018a) BP Energy Outlook 2018

BP (2018b) BP Statistical review of world energy 2018

CEC (2012) National Electric Power Industry Statistical Bulletin. China Electricity Council

Chabukdhara M, Singh OP (2016) Coal mining in northeast India: an overview of environmental issues and treatment approaches. Int J Coal Sci Technol 3(2):87-96

Chen H, Qi H, Long R, Zhang M (2012) Research on 10-year tendency of China coal mine accidents and the characteristics of human factors. Saf Sci 50(4):745-750

Ding S, Zhang Q, Xu W, Guo H, Xiong S, Pan L (2007) Study on calculation method of environmental costs for power generation. Thermal Power Generation (02): $1-4+27$ (in Chinese)
EIA (2017) US Energy Information Administration Annual Energy Outlook 2017

EIA (2018) International Energy Outlook 2018

El-Kordy MN, Badr MA, Abed KA, Ibrahim SMA (2002) Economical evaluation of electricity generation considering externalities. Renew Energy 25(2):317-328

Energy Reform Institute NDRC.P.R.C, China National Renewable Energy Center, Children's Investment Fund Foundation (2019) Energy Transition Trends 2019

EPA (2016) Global mitigation of non- $\mathrm{CO}_{2}$ greenhouse gases: 2010-2030

Fugiel A, Burchart-Korol D, Czaplicka-Kolarz K, Smolinski A (2017) Environmental impact and damage categories caused by air pollution emissions from mining and quarrying sectors of European countries. J Clean Prod 143:159-168

Ghabraie B, Ren G, Smith JV (2017) Characterising the multi-seam subsidence due to varying mining configuration, insights from physical modelling. Int J Rock Mech Min Sci 93:269-279

Giam X, Olden JD, Simberloff D (2018) Impact of coal mining on stream biodiversity in the US and its regulatory implications. Nat Sustain 1(4): 176-183

Gonzalez-Garcia S, Iribarren D, Susmozas A, Dufour J, Murphy RJ (2012) Life cycle assessment of two alternative bioenergy systems involving Salix spp. biomass: bioethanol production and power generation. Appl Energy 95:111-122

Gu Y, Xu J, Chen D, Wang Z, Li Q (2016) Overall review of peak shaving for coal-fired power units in China. Renew Sustain Energy Rev 54:723-731

Hassani F, Nekoovaght P, Gharib N (2016) The influence of microwave irradiation on rocks for microwave-assisted underground excavation. J Rock Mech Geotech Eng 01:1-15

Hong Y-d, Lin B-q, Zhu C-j, Li H (2016) Effect of microwave irradiation on petrophysical characterization of coals. Appl Therm Eng 102:1109-1125

Hsu DD, O'Donoughue P, Fthenakis V, Heath GA, Kim HC, Sawyer P, Choi J-K, Turney DE (2012) Life cycle greenhouse gas emissions of crystalline silicon photovoltaic electricity generation. J Ind Ecol 16:S122-S135

IEA (2016) Key world energy statistics

IEA (2018a) Renewables 2018

IEA (2018b) World Energy Outlook 2018

Jing Y-Y, Bai H, Wang J-J, Liu L (2012) Life cycle assessment of a solar combined cooling heating and power system in different operation strategies. Appl Energy 92:843-853

Krewitt W, Nitsch J (2003) The German Renewable Energy Sources Act-an investment into the future pays off already today. Renew Energy 28(4):533-542

Liu H, Liu Z (2010) Recycling utilization patterns of coal mining waste in China. Resour Conserv Recycl 54(12):1331-1340

Nishimura A, Hayashi Y, Tanaka K, Hirota M, Kato S, Ito M, Araki K, Hu EJ (2010) Life cycle assessment and evaluation of energy payback time on high-concentration photovoltaic power generation system. Appl Energy 87(9):2797-2807

Pan L, Gao T, Xu F, Zhang L (2018) Enhanced robust motion tracking control for 6 degree-of-freedom industrial assembly robot with disturbance adaption. Int $\mathrm{J}$ Control Autom Syst 16(2):921-928

Peng W, Wagner F, Ramana MV, Zhai H, Small MJ, Dalin C, Zhang X, Mauzerall DL (2018) Managing China's coal power plants to address multiple environmental objectives. Nat Sustain 1(11):693-701

Ranjith PG, Zhao J, Ju M, De Silva RVS, Rathnaweera TD, Bandara AKMS (2017) Opportunities and challenges in deep mining: a brief review. Engineering 3(4):546-551 
Restrepo A, Bazzo E, Miyake R (2015) A life cycle assessment of the Brazilian coal used for electric power generation. J Clean Prod 92:179-186

Vrhovcak MB, Tomsic Z, Debrecin N (2005) External costs of electricity production: case study Croatia. Energy Policy 33(11):1385-1395

Wang S (2007) Analysis on the recovery rate of coal resource. Inner Mongolia Coal Econ 02:9-10 (in Chinese)

Wolde-Rufael Y (2010) Coal consumption and economic growth revisited. Appl Energy 87(1):160-167

Wright IA, McCarthy B, Belmer N, Price P (2015) Subsidence from an underground coal mine and mine wastewater discharge causing water pollution and degradation of aquatic ecosystems. Water Air Soil Pollut. https://doi.org/10.1007/s11270-015-25989

Wu H, Wen Q, Hu L, Gong M, Tang Z (2017) Feasibility study on the application of coal gangue as landfill liner material. Waste Manage 63:161-171

Xie H, Gao F, Ju Y, Ge S, Wang G, Zhang R, Gao M, Wu G, Liu J (2017a) Theoretical and technological conception of the fluidization mining for deep coal resources. J China Coal Soc 42(03):547-556 (in Chinese)
Xie H, Ju Y, Gao F, Gao M, Zhang R (2017b) Groundbreaking theoretical and technical conceptualization of fluidized mining of deep underground solid mineral resources. Tunn Undergr Space Technol 67:68-70

Xie H, Ju Y, Gao M, Gao F, Liu J, Ren H, Ge S (2018a) Theories and technologies for in-situ fluidized mining of deep underground coal resources. J China Coal Soc 43(05):1210-1219 (in Chinese)

Xie H, Wang J, Ju Y, Liu J (2018b) Coal industry reform: strategies and directions. Science Press, Beijing (in Chinese)

Xu J, Ma N, Xie H (2017) Ecological coal mining based dynamic equilibrium strategy to reduce pollution emissions and energy consumption. J Clean Prod 167:514-529

Yu S, Wei Y-M, Guo H, Ding L (2014) Carbon emission coefficient measurement of the coal-to-power energy chain in China. Appl Energy 114:290-300

Zhang A, Xu J (2007) Analysis on influence factors of unit cost of coal mining. J China Coal Soc 02:221-224 (in Chinese)

Zhang Y, Shao W, Zhang M, Li H, Yin S, Xu Y (2016) Analysis 320 coal mine accidents using structural equation modeling with unsafe conditions of the rules and regulations as exogenous variables. Accid Anal Prev 92:189-201 